\title{
Resistensi Populasi Hama Bawang Merah Spodoptera exigua (Lepidoptera: Noctuidae) terhadap Klorfluazuron
}

\author{
ABDI NEGARA \\ Balai Pengkajian Teknologi Pertanian (BPTP) Sulawsei Tengah \\ Jalan. Lasoso. No. 62. Biromaru. Palu 94364 \\ (diterima Maret 2005, disetujui A gustus 2005)
}

\begin{abstract}
Resistance of Onion Pest Spodoptera exigua (Lepidoptera: Noctuidae) Populations to Chlorfluazuron. The research was conducted from August 2001 until April 2002 in the Kalitirto Agriculture Training and Development Research Station, Gadjah Mada University. The objective of the research was to determine the resistance level of Spodoptera exigua populations collected from the district of Sanden, Kretek, Wates, Temon, Panjatan, Wonosari, Panggang and Playen (all are in Yogyakarta Province) to chlorfluazuron insecticide. Research was conducted by dipping artificial diets about 30 seconds in insecticide solution and then are used tests two hours after they were air dried. Based on the preliminary test, different concentrations were tested to determine the toxicity of the insecticide to each population. Third instar larvae (five days old) of the first generation were used in bioassays. Each larva with its artificial diet was placed in a plastic cup (diameter 3,5 $\mathrm{cm}$ ). Larval mortality was recorded at 72 hours after exposure. Data was analyzed using probit analysis to determine $\mathrm{LC}_{50}$ values. The results showed that the $\mathrm{LC}_{\mathrm{s0}}$ values of chlorfluazuron againsts eight populations of $S$. exigua at 72 hours after exposure varied from 16,10 ppm (Panggang) to 84,76 ppm (Panjatan). The results suggested that all populations from Panggang, Playen, Kretek, Sanden, Wates, Wonosari and Temon were still susceptible to chlorfluazuron. Populatin from Panjatan indicated to be resistant to chlorfluazuron.
\end{abstract}

KEY WORDS: Resistance, Spodopters exigua, Chlorfluazuron.

\section{PENDAHULUAN}

Di Indonesia, sektor pertanian merupakan salah satu komponen penting dalam perekonomian rakyat, mengingat sebagian masyarakat Indonesia sangat tergantung pada pertanian. Di samping itu, sektor pertanian memegang peranan penting untuk meningkatkan taraf hidup petani pedesaan (Solahuddin, 1999).
Salah satu tanaman sayuran yang mempunyai peranan penting untuk meningkatkan pendapatan petani adalah bawang merah Allium cepa L. (Rahayu dan Berlian, 1994). Produksi bawang merah Indonesia dari tahun 1995-1998 mengalami peningkatan, yaitu dari 592.548 ton pada tahun 1995 menjadi 804.982 ton pada tahun 1998 (BPS, 1999). 
Spodoptera exigua merupakan salah satu hama penting tanaman bawang daun dan bersifat polifag (Omoy, 1988). Di Jawa, hama ini menyerang bawang merah dan Leguminose seperti kacang tanah, krotalaria dan kedelai (Kalshoven, 1981). Hama ini dapat menyerang tanaman bawang merah sejak fase vegetatif sampai saat panen, dan jika serangan berat dapat menyebabkan kerugian hingga 100\%. Hama ini dapat menyelesaikan siklus hidupnya dalam 23 hari (Kalshoven, 1981). Hama ini bukan saja berada di Indonesia tetapi tersebar juga di beberapa negara di dunia antara lain Amerika Serikat, Afrika dan India (Metcalf and Flint, 1962).

Penelitian ini bertujuan untuk mengetahui tingkat resistensi populasi hama ulat bawang merah $S$, exigua di Kecamatan Sanden, Kretek, Wates, Temon, Panjatan, Wonosari, Panggang dan Playen (Propinsi Daerah Istimewa Yogyakarta) terhadap insektisida klorfluazuron.

\section{BAHAN DAN METODE}

\section{Waktu dan Tempat Penelitian}

Penelitian dilaksanakan pada bulan Agustus 2001 sampai dengan bulan April 2002 di laboratorium Kebun Pendidikan Penelitian dan Pengembangan Pertanian (KP4 UGM), Daerah Istimewa Yogyakarta.

\section{Pembuatan Pakan Buatan}

Pembuatan pakan buatan sebagai pakan pengganti $S$. exigua disiapkan dengan menggunakan bahan kacang koro
$(590 \mathrm{~g})$ yang direndam dalam $900 \mathrm{ml}$ air selama 48 jam dan airnya diganti setiap 24 jam, kemudian dihaluskan dengan menggunakan blender dan ditambahkan $12 \mathrm{~g}$ metil $\mathrm{p}$-hidroksi benzoat, $300 \mathrm{~g}$ ragi, $18 \mathrm{~g}$ asam askorbat dan $5 \mathrm{~g}$ asam sorbat. Pada tempat lain $22 \mathrm{~g}$ agar dimasukkan ke dalam $900 \mathrm{ml}$ air dan direbus sampai mendidih. Setelah agak dingin, larutan agar kemudian dituangkan ke dalam blender yang telah diberi bahan pakan dan diaduk hingga rata. Formalin $(8,8 \mathrm{ml})$ ditambahkan ke dalam blender sebelum larutan agar dituangkan. Pakan buatan dituangkan ke dalam wadah plastik yang mempunyai tutup dan dimasukkan ke dalam almari pendingin pada suhu $0^{\circ} \mathrm{C}$ (Singh, 1976). Pakan yang telah jadi diris kecil-kecil berbentuk dadu dan digunakan sebagai pakan ulat $S$. exigua sesuai kebutuhan.

\section{Pembiakan Massal S. exigua}

Tempat pengambilan sampel $S$. exigua adalah delapan kecamatan: Kecamatan Sanden, Kretek, Temon, Wates, Panjatan, Playen, Panggang dan Wonosari. Banyaknya sampel ulat yang diambil dari lapangan untuk setiap lokasi minimal 400 ulat.

Kelompok telur, ulat dan kepompong $S$. exigud dikumpulkan dari lapangan dan dipelihara di laboratorium.

Telur yang diambil dari lapangan di tempatkan pada stoples yang ditutupi kain kasa sampai menetas jadi ulat, kemudian dipindahkan ke dalam botolbotol kecil yang berisi pakan buatan 
(satu ekor ulat per botol). Ulat dari lapangan dimasukkan ke dalam botolbotol kecil berukuran diameter $3,5 \mathrm{~cm}$ dan tingginya $3,5 \mathrm{~cm}$ dan diberi pakan buatan yang telah disiapkan. Kepompong yang diambil dari lapangan ditempatkan pada stoples yang bertutup kain kasa hingga menjadi ngengat, kemudian ngengat tersebut diberi pakan madu yang telah diencerkan dengan pengenceran $10 \mathrm{kali}$ untuk menjaga keperidiannya. Ulat yang baru keluar dari telur dipindahkan ke botol pemeliharaan dan diberi pakan buatan. Ulat $F_{1}$ digunakan sebagai ulat yang di uji.

\section{Pelaksanaan Pengujian}

Ulat yang digunakan dalam pengujian biologi (bioassay) adalah instar tiga (lima hari setelah menetas) dari generasi pertama hasil pembiakan massal di laboratorium.

\section{a. Pengujian Pendahuluan}

$\mathrm{U}_{\mathrm{ji}}$ pendahuluan dilakukan terhadap setiap populasi $S$. exigua. Uji ini dimaksudkan untuk mendapatkan kisaran konsentrasi yang mengakibatkan kematian 5-99\%. Mula-mula konsentrasi yang diuji adalah konsentrasi anjuran yang tertera pada label kemasan yaitu 2 $\mathrm{cc} / \mathrm{l}$ air untuk jenis insektisida kimia yang diuji, dan konsentrasi berikutnya diambil dari konsentrasi yang pertama diencerkan dua kali dan seterusnya. Jumlah ulat yang digunakan untuk setiap konsentrasi adalah 10 ekor, dan setiap ekor dimasukkan dalam satu botol uji. Uji pendahuluan menggunakan lima seri konsentrasi dan satu kontrol. Pengamatan dilakukan pada 72 jam setelah aplikasi dengan menghitung persentase ulat yang mati.

\section{b. Pengujian Utama}

Berdasarkan hasil uji pendahuluan ditentukan lima larutan konsentrasi insektisida yang dapat membunuh larva 5 $99 \%$, dan konsentrasi tersebut digunakan dalam pengujian utama untuk mengestimasi nilai $\mathrm{LC}_{50}$. Pakan buatan dicelup pada masing-masing seri konsentrasi, mulai dari kontrol sampai konsentrasi tertinggi selama 30 detik, di guncang-guncangkan dan setelah itu diletakkan di atas tisu untuk dikeringanginkan selama dua jam. Pakan kemudian dimasukkan ke dalam botol pengujian dengan ulatnya $S$. exigua (1 ekor /botol). Jumlah ulat yang digunakan untuk setiap konsentrasi adalah 10 ekor, dan setiap perlakuan diulang sebanyak tiga kali. Karena efek insektisida (waktu dibutuhkan untuk membunuh) yang diuji terhadap $S$. exigua berbeda, maka pengamatan dilakukan pada 24,48 dan 72 jam setelah aplikasi dengan menghitung persentase ulat yang mati.

\section{Analisis Data}

Analisis data dilakukan dengan menggunakan analisis probit untuk mendapatkan nilai $\mathrm{LC}_{50}$. Apabila mortalitas pada perlakuan kontrol lebih besar dari $0 \%$ dan lebih kecil dari $20 \%$ maka mortalitas ulat pada perlakuan dikoreksi dengan formula Abbott (1925) 
cit Trisyono dan Whalon $(1997,1999)$ dengan rumus sebagai berikut:

$$
P=\frac{P^{\prime}-C}{100-C} \times 100 \%
$$

$\mathrm{P}=$ mortalitas terkoreksi $(\%)$

$\mathrm{P}^{\prime}=$ mortalitas hasil pengamatan pada setiap perlakuan insektisida (\%)

$\mathrm{C}=$ mortalitas pada kontrol (\%)

Perbandingan tingkat kepekaan suatu populasi $S$. exigua dengan populasi yang lainnya terhadap suatu insektisida dilakukan dengan perhitungan Resistance Ratio ( $R \mathrm{R})$ dengan rumus:

$$
R R=\frac{L_{50} \text { Populasi Uji }}{L_{50} \text { Populasi Rentan }} \times 100 \%
$$

Uji beda nyata kepekaan populasi terhadap insektisida dibandingkan berdasarkan nilai selang kepercayaan $95 \%$. Dua nilai $\mathrm{LC}_{50}$ akan berbeda nyata apabila nilai selang kepercayaan $95 \%$ (batas atas dan batas bawah) tidak tumpang tindih (Marcon etal, 1999).

\section{HASIL DAN PEMBAHASAN}

Resistensi Populasi S. exigua terhadap Klorfluazuron

Nilai LC $_{50}$ insektisida klorfluazuron pada pengamatan 72 jam setelah pemaparan terhadap delapan populasi $S$. exigua bervariasi $16,10-84,76$ ppm (Tabel 1).

Populasi asal Panjatan berbeda nyata terhadap populasi asal Panggang, Playen, Kretek dan Sanden, tetapi tidak berbeda nyata terhadap Temon, Wono sari dan Wates. Populasi asal Temon,

Tabel 1. Resistensi beberapa populasi Spodoptera exigua di DIY terhadap klorfluazuron setelah 72 jam pemaparan

\begin{tabular}{ccccccc}
\hline \hline $\begin{array}{c}\text { Asal } \\
\text { Populasl }\end{array}$ & $\begin{array}{c}\text { Jumlah } \\
\text { Serangga } \\
\text { Uji }\end{array}$ & Slope \pm SE & LC 50 (SK95\%) ppm & $\chi^{2}$ hitung & $\chi^{2}$ tabel & RR \\
\hline Panjatan & 180 & $1,150 \pm 0,17$ & $84,76(55,59-129,53) \mathrm{c}$ & 1,13 & 7,8 & 5,3 \\
Temon & 180 & $1,150 \pm 0,24$ & $58,41(40,70-83,83)$ bc & 2,17 & 7,8 & 3,6 \\
Wonosari & 180 & $1,54 \pm 0,37$ & $57,79(39,72-84,07)$ bc & 4,69 & 7,8 & 3,6 \\
Wates & 180 & $1,163 \pm 0,20$ & $53,35(37,71-75,42)$ bc & 0,30 & 7,8 & 3,3 \\
Sanden & 180 & $1,192 \pm 0,37$ & $32,38(19,38-54,10)$ ab & 4,55 & 7,8 & 2,0 \\
Kretek & 180 & $1,49 \pm 0,20$ & $29,27(20,34-42,13)$ ab & 1,50 & 7,8 & 1,8 \\
Playen & 180 & $1,26 \pm 0,25$ & $22,92(14,17-37,09)$ a & 2,33 & 7,8 & 1,4 \\
Panggang & 180 & $1,13 \pm 0,20$ & $16,10(7,17-36,12)$ a & 1,23 & 7,8 & 1,0 \\
\hline
\end{tabular}

Keterangan : Nilai LC $_{50}$ yang diikuti huruf yang sama tidak berbeda nyata karena batas bawah dan batas atas nilai 95\% selang kepercayaan (SK) tumpang tindih (Marcon ot al., 1999).

$R R=$ Raslo Resistensi ( $L C_{50}$ populasi yang dibandingkan: $L C_{s 0}$ populasi Panggang) 


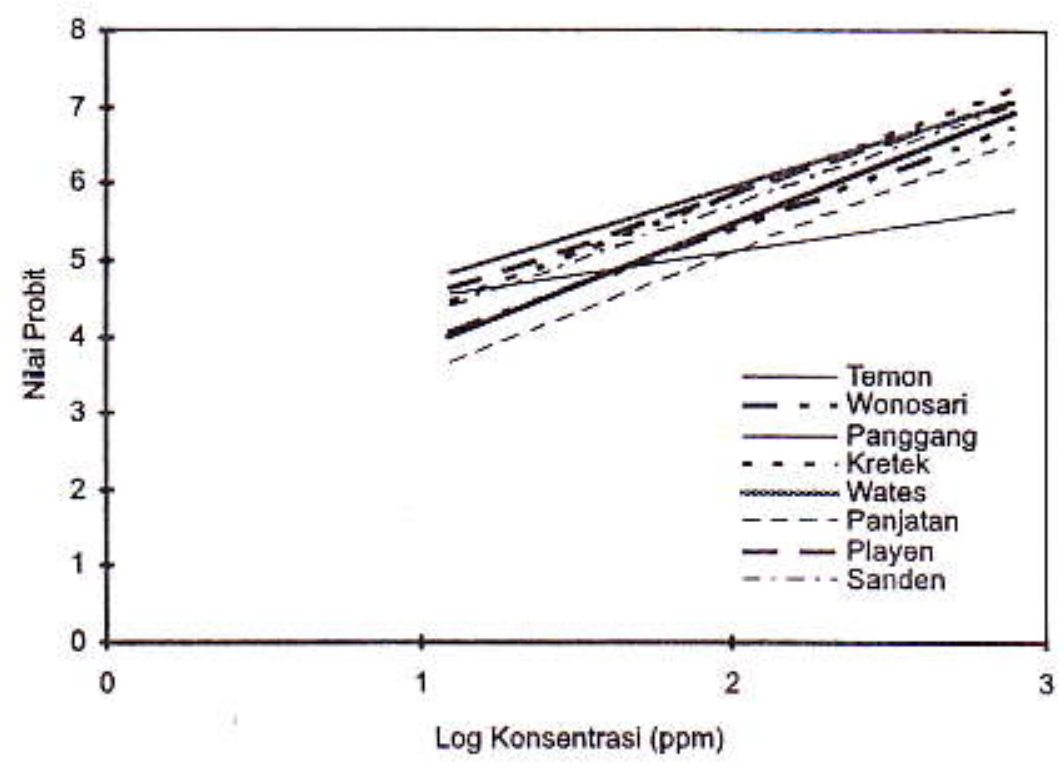

Gambar 1. Hubungan regiesi konsentrasi klorfluazuron dan mortalltas Spodoptera exigua pada pengamatan 72 jam setelah pemaparan

Wonosari dan Wates berbeda nyata terhadap populasi asal Panggang dan Playen. Populasi asal Sanden dan Kretek berbeda nyata terhadap populasi asal Panjatan, tetapi tidak berbeda nyata terhadap Panggang, Playen, Wates, Wonosari dan Temon.

Nilai rasio resistensi menunjukkan bahwa $S$. exigua asal Panjatan mempunyai rasio resistensi paling besar (Tabel 1). Kurang pekanya populasi $S$. exigua asal Panjatan terhadap klorfluazuron diduga disebabkan oleh beberapa faktor: a) penggunaan insektisida klorfluazuron yang terus-menerus pada musim tanam bawang merah, b) frekuensi penyemprotan lebih banyak dibanding dengan wilayah lain.

Garis regresi yang menyatakan hubungan antara tingkat konsentrasi insektisida klorfluazuron dan mortalitas ulat $S$. exigua untuk tiap daerah populasi pada pengamatan 72 jam setelah pemaparan dapat dilihat pada Gambar 1. Respon S. exigua terhadap insektisida klorfluazuron bersifat homogen, oleh karena $\chi^{2}$ hitung $<\chi^{2}$ tabel, sehingga dapat disimpulkan bahwa garis regresi probit ini secara bermakna menggambarkan hasil penelitian ini.

Tingkat kepekaan populasi $S$. exigua terhadap klorfluazuron sangat bervariasi. Hal ini menunjukkan bahwa populasi asal Panjatan kurang peka terhadap klorfluazuron karena sudah mendekati konsentrasi anjuran (2 cc/l). Berdasarkan hal tersebut di atas, maka insektisida klorfluazuron dianjurkan dirotasi dengan insektisida lain. Jika klorfluazuron masih digunakan, ke- 
mungkinan besar akan terjadi resisistensi pada generasi berikutnya. Menurut Soejitno et al. (1994), apabila nilai LC $_{\text {so }}$ insektisida yang diuji empat kali lipat nilai $\mathrm{LC}_{\mathrm{s} 0}$ insektisida pembanding maka insektisida tersebut dinyatakan kurang efektif lagi. Hal serupa dikemukakan oleh Waterhouse (1976) cit Meidi awarman (1992) yang menyatakan bahwa peningkatan $\mathrm{LC}_{50}$ dengan kelipatan 4-5 kali dari populasi pembanding akan menyebabkan pengendalian tidak efektif lagi. Granett et al. (1983) melaporkan bahwa klorfluazuron merupakan salah satu insektisida penghambat kitin yang mempunyai toksisitas lebih tinggi dibanding diflubenzuron dan triflumuron. Mereka melaporkan bahwa $\mathrm{LC}_{50}$ klorfluazuron terhadap ulat $S$. exigua adalah $0,23 \mathrm{ppm}$, sedangkan $\mathrm{LC}_{30}$ diflubenzuron $1,4 \mathrm{ppm}$, dan triflumuron 8,1 ppm. Laporan lain menyebutkan bahwa klorfluazuron pada Lepidoptera dan Coleoptera lebih toksik dibanding diflubenzuron dan triflumuron karena klorfluazuron dapat bertahan pada tubuh serangga (Mizui, 1985). Magalona ot al. (1990) mengemukakan bahwa resistensi merupakan menurunnya tanggapan yang dapat terjadi pada populasi spesies serangga atau tumbuhan terhadap pestisida. Menurut Gould (1984), mekanisme terjadinya resistensi serangga hama terhadap insektisida ditandai dengan menurunnya daya bunuh insektisida yang digunakan. Dengan demikian secara tidak sadar petani selalu meningkatkan dosis dan memperpendek frekuensi penyemprotan. Hama yang mendapat perlakuan demikian akan memiliki tanggapan yang cepat terhadap proses terjadinya resistensi.

Usaha untuk mengatasi timbulnya resistensi serangga hama $S$. exigua terhadap insektisida, antara lain dilakukan dengan memodifikasi cara aplikasi insektisida, misalnya dengan cara menerapkan ambang pengendalian, penggunaan dosis yang tepat dan perbaikan cara penyemprotan. Berkurangnya penggunaan insektisida kimia karena penerapan ambang ekonomi, akan menyebabkan berkurangnya tekanan seleksi yang melahirkan strain serangga resisten (Suhardi et al., 1994).

\section{KESIMPULAN}

Tingkat resistensi insektisida klorfluazuron dengan Nilai LC $_{50}$ pada pengamatan 72 jam setelah pemaparan terhadap delapan populasi $S$. exigua bervariasi dari 16,10 ppm (Panggang) sampai 84,76 ppm (Panjatan), dengan nilai rasio resitensi berkisar $1,0-5,3 \mathrm{kali}$.

Populasi asal Panggang, Playen, Kretek, Sanden, Wates, Wonosari dan Temon masih berpotensi menggunakan insektisida klorfluazuron, sedangkan populasi asal Panjatan sudah resisten terhadap insektisida klorfluazuron.

\section{UCAPAN TERIMA KASIH}

Ucapan terima kasih di sampaikan kepada Dr. Ir. Y. Andi Trisyono, M.Sc dan Ir. Muhammad Rosyid, M.Sc, Dosen Pascasarjana Program Studi Ilmu Hama Tumbuhan, Jurusan Ilmu-Ilmu 
Pertanian Universitas Gadjah Mada

Yogyakarta atas selesainya penelitian ini.

\section{DAFTAR PUSTAKA}

BPS. 1999. Dacrah Istimewa Yogyakarta dalam Angka. Yogyakarta. $574 \mathrm{hal}$.

Finney, D. J. 1971. Probit Analysis, 3rd edition. Cambridge University Press, London. 333 p.

Granett, J. B. S. Ershadi, and M. J. Hejazi. 1983. Some Parameters of Benzoylphenyl Urea Toxicity to Beet Armyworms (Lepidoptera: Noctuidae). Journal of Economic Entomology 76(3): 399-402.

Gould, F. 1984. Role of Behavior in The Evaluation of Insect Adaptation to Insecticides and Resistance Host Plants. Bulletin of the Entomological Society of America 30: 34-40.

Kalshoven, L. G. E. 1981. The Pest of Crops in Indonesia. (Diterjemahkan oleh Van der Laan). PT. Ichtiar Baru - Van Hoeve, Jakarta. ${ }^{701} \mathrm{P}$.

Magalona, E. D., M. Suhardjan, and H. Lumbantobing. 1990. Pesticides in Estate Crop Protection in Indonesia. Directorate General Estate Crops, Jakarta. 220 p.

Marcon, P. C. G., L. J. Young, K. L. Steffey, and B. D. Siegfricd. 1999. Baseline Susceptibility of European Corn Borer (Lepidoptera: Crambidae) to Bacillys thwringiensis Toxins. Journal of Economic Entomology 92(2): 279-285.

Metcalf, C. L., and W. F. Plint. 1962. Destructive and Useful Insect. Mc. Graw Hill Book Company, Inc, New York. 1087 p.

Mizui, T. 1985. Chitin Synthesis Inhibitor: Benzoylarylurea Insecticides. Japan Pesti cides Information 47:3-7.

Meidiawarman. 1992. Perbandingan Tingkat Resistensi Ulat Grayak Spodoptera exigua
(Hübner) pada Tanaman Bawang Merah terhadap Tiga Jenis Insektisida di Pulau Lombok. Tesis Fakultas Pertanian Pascasarjana Universitas Gadjah Mada, Yogyakarta. 64 hal.

Omoy, R. T. 1988. Pengujian Beberapa Macam Insektisida terhadap Hama Spodoptera exigwa (Hübner) pada Bawang Daun. Buletin Penelitian Hortikultura XV (3): 117120.

Rahayu, E., dan Berlian. 1994. Bawang Merah. Penebar Swadaya, Jakarta. 94 hal.

Singh, P. 1976. Artificial Diets for Insects, Mites and Spiders. Entomology Division Depart ment of Scientific and Industrial Research Aucland, New Zealand. 594 p.

Solahuddin. 1999. Profil Pertanian dalam Angka. Departemen Pertanian Jakarta. 325 hal.

Socjino, J., I. M. Samudra, dan D. Kilin. 1994. Kajian Resistensi Penggerek Batang Padi (Scirphopaga innotata) terhadap Insekrisida Karbofuran di Jalur Pantura. Hasil Penelitian Pendukung Pengendalian Hama Terpadu. Kerjasama Kelompok Kerja Penelitian dan Pengembangan PHT. BAPPENAS dan BALITHOR. hal. 323-331.

Suhardi, T., Keostoni, dan T. A. Soctiharso. 1994. Pengujian Teknologi Pengendalian Hama dan Penyakit Terpadu pada Bawang Merah Berdasarkan Nilai Ambang Pengendalian dan Modifikasi Tipe Nozzle Alat Semprot. Buletin Penelitian Hortikultura 26 (4):100107.

Trisyono, A., and M. E. Whalon. 1997. Fitness Costs of Resistance to Bacillus thuringiensis in Colorado Potato Beetle (Colcoptera: Chrysomelidac). Journal of Economic Entomology 90 (2): 267-271.

Trisyono, A., and M. E. Whalon. 1999. Toxicity of Neem Applied Alone and Combination with Bacillus tburingiensis to Colorado Potato Beetle (Coleoptera: Crysomelidae). Journal of Economic Entomology 92 (6): 1281-1288. 